\title{
Borderline oligohydramnios in term pregnancy and it's relation with pregnancy outcome
}

\author{
M. Vennila*, S. Deepika
}

Department of Obstetrics and Gynecology, Tirunelveli Medical College and Hospital, Tirunelveli, Tamil Nadu, India

Received: 15 December 2020

Accepted: 31 December 2020

\section{*Correspondence:}

Dr. M. Vennila,

E-mail: vennilamagnesh@gmail.com

Copyright: $\odot$ the author(s), publisher and licensee Medip Academy. This is an open-access article distributed under the terms of the Creative Commons Attribution Non-Commercial License, which permits unrestricted non-commercial use, distribution, and reproduction in any medium, provided the original work is properly cited.

\begin{abstract}
Background: Oligohydramnios can lead to contamination of amniotic fluid, fetal distress, neonatal asphyxia, aspiration pneumonia, increased perinatal mortality and adverse pregnancy outcomes. Because of atypical clinical symptoms, the critical point is to treat patients with oligohydramnios in late pregnancy. The objectives of the research were to study the mode of delivery/rate of operative interference/incidence of cesarean section due to fetal distress/non-reassuring fetal heart rate status in cases of term pregnancy with borderline amniotic fluid index (AFI), and to study the perinatal outcome in cases of term pregnancy with borderline AFI.

Methods: The study is a prospective comparative study to be conducted in patients attending antenatal clinic at department of obstetrics and gynaecology, Tirunelveli government medical college hospital from from January 2018 till January 2019 (12 months). Data collected with regards to age, demographic characteristics, and socioeconomic status, detailed history including patient's complaints, duration of complaints, menstrual and obstetric history, significant past, family and personal history. 265 cases of borderline oligohydramnios were detected of which 150 cases were selected for the study after applying exclusion criteria.

Results: APGAR scores between the two groups. The mean APGAR scores of the normal group were $8.3 \pm 0.7$ and the same of the borderline AFI group was 8.0 0 .9. The difference between the means was statistically highly significant $(\mathrm{p}<0.01)$.

Conclusions: Cumulative analysis of various studies, it will be reasonable to conclude that antepartum surveillance for borderline oligohydramnios is indicated in cases associated with fetal growth restriction or suboptimal fetal growth.
\end{abstract}

Keywords: Oligohydramnios, Neonatal asphyxia, Amniotic fluid, Aspiration pneumonia

\section{INTRODUCTION}

Oligohydramnios occurs in approximately $4.5 \%$ of all pregnancies and severe oligohydramnios occurs in $0.7 \%$ of all pregnancies. Oligohydramnios is more common in pregnancies beyond term as the AFI normally decreases at term. ${ }^{1}$ Oligohydramnios complicates as many as $12 \%$ of pregnancies that last beyond 41 weeks. Amniotic fluid is the clear liquid surrounding the developing fetus in the mother's womb. It prevents the developing fetus from cord compression and provides a cushion for the fetus and thus plays a significant role in fetal growth. By the virtue of being bacteriostatic, it prevents intraamniotic sepsis. The levels of amniotic fluid depend on the exchange between fetus, mother and placenta. $^{2}$ Disturbances in such regulations can result in polyhydramnios/oligohydramnios. These disorders arise from pathological feto-maternal conditions and hence may affect fetal well-being. The levels of amniotic fluid are assessed by real-time ultrasound resulting in early intervention if needed. The amniotic fluid that surrounds the developing fetus in the amniotic sac protect and cushions the fetus and play an important role in fetal growth. By the virtue of being bacteriostatic, amniotic fluid aids in preventing intraamniotic sepsis. The levels of amniotic fluid depend upon water exchange between fetus, 
placenta, and mother. ${ }^{3}$ Any deviations from these regulatory processes result in oligohydramnios/polyhydramnios. Assessment of amniotic fluid levels has been made possible due to realtime ultrasonography. Phelan et al described the amniotic fluid index (AFI) which described oligohydramnios as $\mathrm{AFI}<5$. Borderline oligohydramnios as $\mathrm{AFI}=5.1-8 \mathrm{~cm}$; polyhydramnios as AFI $>20 \mathrm{~cm}$. Studies re-veal increased incidence of adverse perinatal outcomes among women with borderline AFI. In the first half of pregnancy, amniotic fluid is produced from both maternal and fetal compartments. Thus, in early gestation, amniotic fluid is a dialysate identical to maternal and fetal plasma but with reduced protein concentration. ${ }^{5}$ During the first half of pregnancy, water and other molecules may get transferred across amnion-transmembranous flow; or through fetal skin-transcutaneous; across fetal vessels - intra membranous flow. By the second trimester, owing to keratinization of fetal skin, further diffusion can't take place due to impermeability. Now, amniotic fluid is derived from fetal urine. ${ }^{6}$ Fetal urine production begins between 8 and 11 weeks gestation but it becomes a major amniotic fluid component only after the second trimester and that's why severe oligohydramnios does not manifest until 18 weeks in cases of fetuses with renal anomalies. The fetal urine is hypotonic (80-140 most/liter). Hence, amniotic fluid is progressively hypotonic (250-260 most/liter). The average amniotic fluid secretion range from $500-700 \mathrm{ml} /$ day by term and declines after 40 weeks gestation. ${ }^{7}$.

\section{METHODS}

The present study was undertaken at Tirunelveli government medical college hospital. This is a prospective comparative study done from 01 January 2018 till 31 January 2019 for one year. The study involved analyzing and comparing mode of delivery and perinatal outcomes in women of term pregnancy with borderline AFI $(5-8 \mathrm{~cm})$ and those with normal AFI. A total of 150 women with borderline AFI and 150 women with normal AFI were included in the study. 265 cases of borderline oligohydramnios were detected of which 150 cases were selected for the study after applying exclusion criteria. The gestational age was calculated from the first day of the last menstrual period or using ultrasound before 12 weeks of gestation. An ultrasound report made by one physician was used to determine the accuracy of borderline AFI. Normal amniotic fluid volume was defined as AFI 8-24 cm and borderline amniotic fluid volume as AFI $5-8 \mathrm{~cm}$ and at least two sonographic measurements after 28 weeks were required to confirm borderline AFI.

\section{Inclusion criteria}

The following criteria was considered for inclusion in the study: age of the mother 18-35 years, gestational age 3742 weeks, singleton gestation with cephalic presentation, AFI $5-8 \mathrm{~cm}$ and AFI $8-24 \mathrm{~cm}$ as controls, and intact membranes.

\section{Exclusion criteria}

The following criteria was considered for exclusion in the study: gestational age $<37$ weeks, associated fetal malformation, ruptured membranes, multiple gestation, AFI $<5 \mathrm{~cm}$, post-term $>42$ weeks of gestation, malpresentation, uterine scar due to previous lower segment caesarean section (LSCS), myomectomy, and hysterectomy.

The same inclusion and exclusion criteria were applied to select pregnant women with normal AFI: $8.1-24 \mathrm{~cm}$ as well as those with normal AFI. Informed written consent was obtained for the study. Detailed history and complete clinical examination was done and both groups were followed up during labor and delivery and adverse perinatal outcomes were studied which included intrapartum fetal distress, presence of meconium-stained liquor during labor and delivery, APGAR scores $<7$ at 5 minutes, features of IUGR birth weight $<10$ oligohydramnios occurs in approximately $4.5 \%$ of all pregnancies and severe oligohydramnios occurs in $0.7 \%$ of all pregnancies. Oligohydramnios is more common in pregnancies beyond term as the AFI normally decreases at term.

\section{Statistical analysis}

The study subjects namely borderline AFI and normal AFI were described in terms of averages in respect to their continuous variables. The continuous variables were interpreted between the groups by student independent " $\mathrm{t}$ " test. The categorical variables were described in terms of percentages and interpreted by an appropriate nonparametric test such as $\chi 2$ (Chi-square). The above statistical procedures were performed with help of the statistical package namely IBM statistical package for the social sciences (SPSS) statistics-20. The p values less than or equal to $0.05(\mathrm{p} \leq 0.05)$ were considered statistically significant.

\section{RESULTS}

The present study was conducted in the department of obstetrics and gynecology from January 2018 till January 2019. A total of 2100 deliveries were conducted during the study period out of which 150 cases with borderline oligohydramnios were selected for the study with AFI between 5.1 to $8 \mathrm{~cm}$; a total of 300 women were enrolled in this study. Of these, 150 women were in the borderline AFI group. 150 women were selected in the normal AFI group for comparison.

Table 1 shows the age-wise incidence of borderline oligohydramnios and normal AFI among pregnant women. The highest age-wise incidence occurs at 20-24 years with a mean of $23.9 \pm 3.9$ years for normal subjects and a mean of 23.8 \pm 3.6 years for women with borderline AFI. The mean gestational ages of the normal group were 39.4 \pm 1.2 weeks and in the borderline AFI group, the mean GA was 
$39.3 \pm 1.2$ weeks. The difference between the two groups was not statistically significant $(\mathrm{p}>0.05)$.

Table 2 shows the comparison between the two groups in respect of their gravid. The results revealed that there was no statistically significant difference between the two groups $(\mathrm{p}>0.05)$.

Table 3 compares the parity between the two groups. The parity of both groups was not statistically significant $(\mathrm{p}>0.05)$.

Table 4 compares the mode of delivery between the two groups. The normal deliveries between the groups were 104 and 85. The assisted deliveries were 25 and 18 between the two groups. The LSCS of both groups were 21 and 47 . The differences between the two groups were statistically highly significant $(\mathrm{p}<0.01)$.

Table 5 compares the indication of LSCS between the two groups. The caesarean section rates due to fetal distress and non-reassuring FHR (in cardiotocography) were significantly more among the borderline AFI subjects than the normal group with high statistical significance $(\mathrm{p}<0.01)$.
Table 6 compares the rates of MSAF between the two groups. The positive MSAF was $15.7 \%$ of the borderline and the same of the normal was $23.7 \%$. The difference between them was statistically highly significant $(p<0.01)$. The rates of meconium staining of amniotic fluid between both the groups. The rates of MSAF were higher among the borderline AFI group as compared to those with normal AFI.

Table 7 compares the APGAR score between the two groups. The mean APGAR scores of the normal group were $8.3 \pm 0.7$ and the same of the borderline AFI group was $8.0 \pm 0.9$. The difference between the means was statistically highly significant $(\mathrm{p}<0.01)$. The rates of APGAR score $<7$ at 5 minutes were more among the borderline AFI group as compared to those with normal AFI.

Table 8 shows that NICU admissions were more among borderline AFI group as compared to those with normal AFI though this was not found to be statistically significant, two neonatal deaths were observed in women of borderline oligohydramnios group. Causes of the death being meconium aspiration syndrome and birth asphyxia with hypoxic ischaemic encephalopathy. There were no perinatal deaths among women with normal AFI.

Table 1: Comparison of mothers' age between the two groups.

\begin{tabular}{|c|c|c|c|c|}
\hline \multirow{2}{*}{ Age group (in years) } & \multicolumn{2}{|l|}{ Normal } & \multicolumn{2}{|c|}{ Borderline AFI } \\
\hline & Frequency & Percentage & Frequency & Percentage \\
\hline$<20$ & 14 & 9.3 & 13 & 8.7 \\
\hline $20-24$ & 72 & 48.0 & 80 & 53.3 \\
\hline $25-29$ & 51 & 34.0 & 46 & 30.7 \\
\hline $30-34$ & 13 & 8.7 & 11 & 7.3 \\
\hline Total & 150 & 100.0 & 150 & 100.0 \\
\hline Mean \pm SD & $23.9 \pm 3.9$ & & $23.8 \pm 3.6$ & \\
\hline Significance & \multicolumn{4}{|c|}{$" \mathrm{t} "=0.093, \mathrm{df}=298, \mathrm{p}=0.926$} \\
\hline
\end{tabular}

Table 2: Comparison of gravida between the two groups.

\begin{tabular}{|c|c|c|c|c|c|c|c|}
\hline \multirow{2}{*}{ Gravida } & \multicolumn{2}{|c|}{ Normal } & \multicolumn{2}{|c|}{ Borderline AFI } & \multicolumn{2}{|c|}{ Total } & \multirow{2}{*}{ Results } \\
\hline & No & $\%$ & No & $\%$ & No & $\%$ & \\
\hline 1 & 82 & 27.3 & 91 & 30.3 & 173 & 57.7 & \multirow{5}{*}{$\begin{array}{l}\chi 21.369 \\
d f=3 P=0.713\end{array}$} \\
\hline 2 & 48 & 16.0 & 44 & 14.7 & 92 & 30.7 & \\
\hline 3 & 15 & 5.0 & 11 & 3.7 & 26 & 8.6 & \\
\hline 4 & 5 & 1.7 & 4 & 1.3 & 9 & 3.0 & \\
\hline Total & 150 & 50.0 & 150 & 50.0 & 300 & 100.0 & \\
\hline
\end{tabular}

Table 3: Comparison of parity between the two groups.

\begin{tabular}{|c|c|c|c|c|c|c|c|}
\hline \multirow{2}{*}{ Parity } & \multicolumn{2}{|c|}{ Normal } & \multicolumn{2}{|c|}{ Borderline AFI } & \multicolumn{2}{|c|}{ Total } & \multirow{2}{*}{ Results } \\
\hline & No & $\%$ & No & $\%$ & No & $\%$ & \\
\hline $\mathbf{0}$ & 82 & 27.3 & 91 & 30.3 & 173 & 57.7 & \multirow{5}{*}{$\begin{array}{l}\chi 2=1.369 \\
\mathrm{df}=3 \\
\mathrm{P}=0.713\end{array}$} \\
\hline 1 & 48 & 16.0 & 44 & 14.7 & 92 & 30.7 & \\
\hline 2 & 15 & 5.0 & 11 & 3.7 & 26 & 8.6 & \\
\hline 3 & 5 & 1.7 & 4 & 1.3 & 9 & 3.0 & \\
\hline Total & 150 & 50.0 & 150 & 50.0 & 300 & 100.0 & \\
\hline
\end{tabular}


Table 4: Comparison of mode of delivery between the two groups.

\begin{tabular}{|c|c|c|c|c|c|c|c|}
\hline \multirow{2}{*}{$\begin{array}{l}\text { Mode of } \\
\text { delivery }\end{array}$} & \multicolumn{2}{|c|}{ Normal } & \multicolumn{2}{|c|}{ Borderline AFI } & \multicolumn{2}{|c|}{ Total } & \multirow[b]{2}{*}{ Results } \\
\hline & No & $\%$ & No & $\%$ & No & $\%$ & \\
\hline Normal & 104 & 34.7 & 85 & 28.3 & 189 & 63.0 & \multirow{4}{*}{$\begin{array}{l}\chi 2=12.991 \\
\mathrm{df}=2 \mathrm{P}=0.002\end{array}$} \\
\hline Assisted & 25 & 8.3 & 18 & 6.0 & 43 & 14.3 & \\
\hline LSCS & 21 & 7.0 & 47 & 15.7 & 68 & 22.7 & \\
\hline Total & 150 & 50.0 & 150 & 50.0 & 300 & 100.0 & \\
\hline
\end{tabular}

Table 5: Comparison of indication of LSCS between the two groups.

\begin{tabular}{|c|c|c|c|c|c|c|c|}
\hline \multirow{2}{*}{ Indication for LSCS } & \multicolumn{2}{|c|}{ Normal } & \multicolumn{2}{|c|}{ Borderline AFI } & \multicolumn{2}{|c|}{ Total } & \multirow{2}{*}{ Results } \\
\hline & No & $\%$ & No & $\%$ & No & $\%$ & \\
\hline Arrest of descent & 0 & 0.0 & 3 & 4.4 & 3 & 4.4 & \multirow{8}{*}{$\begin{array}{l}\chi 2=12.991 \\
\mathrm{df}=2 \\
\mathrm{P}=0.002\end{array}$} \\
\hline CPD & 7 & 10.3 & 10 & 14.7 & 17 & 25.0 & \\
\hline Deep transverse arrest & 1 & 1.5 & 0 & 0.0 & 1 & 1.5 & \\
\hline Failure to progress & 0 & 0.0 & 7 & 10.3 & 7 & 10.3 & \\
\hline Fetal distress & 6 & 8.8 & 14 & 20.6 & 20 & 29.4 & \\
\hline Nonprogression of labour & 5 & 7.4 & 0 & 0.0 & 5 & 7.4 & \\
\hline Non reassuring FHR & 2 & 2.9 & 13 & 19.1 & 15 & 2.2 & \\
\hline Total & 21 & 30.9 & 47 & 69.1 & 68 & 100.0 & \\
\hline
\end{tabular}

Table 6: Comparison of MSAF between the two groups.

\begin{tabular}{|c|c|c|c|c|c|c|c|}
\hline \multirow{2}{*}{ MSAF } & \multicolumn{2}{|c|}{ Normal } & \multicolumn{2}{|c|}{ Borderline AFI } & \multicolumn{2}{|c|}{ Total } & \multirow{2}{*}{ Results } \\
\hline & No & $\%$ & No & $\%$ & No & $\%$ & \\
\hline- & 126 & 42.0 & 103 & 34.3 & 229 & 76.3 & \multirow{3}{*}{$\begin{array}{l}\chi 2=9.761 \\
\mathrm{df}=1 \mathrm{P}=0.002\end{array}$} \\
\hline+ & 24 & 8.0 & 47 & 15.7 & 71 & 23.7 & \\
\hline Total & 150 & 50.0 & 150 & 50.0 & 300 & 100.0 & \\
\hline
\end{tabular}

Table 7: Comparison of APGAR score between the two groups.

\begin{tabular}{|lllll|}
\hline APGAR score & Normal & \multicolumn{3}{c|}{ Borderline AFI } \\
\hline $\mathbf{5}$ & Frequency & $\mathbf{\%}$ & Frequency & \% \\
\hline $\mathbf{6}$ & 0 & 0.0 & 2 & 1.3 \\
\hline $\mathbf{7}$ & 4 & 2.7 & 9 & 6.0 \\
\hline $\mathbf{8}$ & 6 & 4.0 & 13 & 8.7 \\
\hline $\mathbf{9}$ & 84 & 56.0 & 82 & 54.7 \\
\hline Total & 56 & 37.3 & 44 & 29.3 \\
\hline Mean \pm SD & 150 & 100.0 & $8.0 \pm 0.9$ & 100.0 \\
\hline Significance & $8.3 \pm 0.7$ & & & \\
\hline
\end{tabular}

Table 8: Comparison of perinatal outcomes in both groups.

\begin{tabular}{|lll|}
\hline Comparison & $\begin{array}{l}\text { Borderline } \\
\text { oligohydramnios } \\
(\%)\end{array}$ & $\begin{array}{l}\text { Normal } \\
\text { liquor } \\
\text { volume }\end{array}$ \\
\hline Birth weight $<\mathbf{2 . 5} \mathbf{~ k g}$ & $17(11.3)$ & $11(7.3)$ \\
\hline $\begin{array}{l}\text { Apgar score }<\mathbf{7} \text { at } \mathbf{5} \\
\text { minutes of birth }\end{array}$ & $11(7.3)$ & $4(2.6)$ \\
\hline NICU admission & $19(12.6)$ & $10(6.6)$ \\
\hline Neonatal death & 2 & - \\
\hline
\end{tabular}

\section{DISCUSSION}

This is a prospective comparative study conducted at the department of obstetrics and gynaecology at Tirunelveli medical college hospital for one year. The study population was divided into two groups. The first group was those women with borderline AFI $(5-8 \mathrm{~cm})$ and the second group was those women with normal AFI (5-25 $\mathrm{cm})$. Women were followed up through their antenatal and most importantly during their intrapartum period. Their course of labour was monitored with the help of CTG. All cases had spontaneous onset of labour while at the time of admission which was allowed for spontaneous progression. No labour inductions were needed for any of the study population. Only acceleration with syntocinon was done when the women entered into the active phase of labour. Partograms were plotted for all cases and effective monitoring of labour was done. Amnio infusion was carried out for those women who had meconium staining of amniotic fluid with a reassuring CTG pattern at the 
active phase of labour. Newborn's condition at the time of birth was analyzed namely birth weight, APGAR score, and rates of NICU admissions, and their course was followed through the postpartum period. Amniotic fluid volume quantification is a vital part of antenatal fetal surveillance. ${ }^{8}$ Camu et al who originally described the concept of AFI, have introduced the term borderline amniotic fluid volume when AFI was between $8 \mathrm{~cm}$. the use of the single deepest pocket method over AFI estimation. However, ACOG recommends AFI estimation as the best method to assess the amniotic fluid volume and thus validating our study in current clinical settings. A Cochrane review also reported that both methods were equally not efficacious in preventing adverse perinatal outcomes but these are the best non-invasive methods available currently for estimation of amniotic fluid volume. ${ }^{9}$ In our study, the incidence of borderline oligohydramnios was found to be $12.5 \%$. A major indicator of fetal distress was the meconium staining of amniotic fluid. The rates of MSAF in women with borderline oligohydramnios during labor was $31.3 \%$ in our study which is higher than rates of MSAF for women with normal AFI in our study. ${ }^{10}$ The rates of MSAF were $30.76 \%$ in studies by Ehrenthal et al showed the incidence of $26.98 \%$ and studies by Conway et al showed an incidence of $24 \%$. These studies reported that women with borderline oligohydramnios showed higher rates of MSAF as compared to those with normal AFI. ${ }^{11}$ Studies by Nike et al did not reveal any significant difference in rates of meconium staining of amniotic fluid between women with borderline oligohydramnios and women with normal AFI. ${ }^{12}$ In my study, the rate of cesarean section was higher among women with borderline oligohydramnios which was $31.3 \%$ which was significantly higher when compared to the rates of cesarean section in women belonging to the normal AFI group. ${ }^{13}$ Studies by Haas et al revealed the rate of cesarean section to be $62 \%$ among women with borderline AFI which was quite higher when compared to any study. This could be explained by the fact that $12 \%$ of cases underwent elective cesarean section owing to oligohydramnios. Luo et al reported that the rate of cesarean section was higher in the borderline oligohydramnios group. However, there was no increased incidence of neonatal deaths or fetal distress in the borderline oligohydramnios group in their study. ${ }^{14}$ Hashimoto et al found that cesarean section for fetal distress was $44 \%$ in women with borderline AFI and it was significantly higher than those with normal AFI. Hence there must be heightened antepartum surveillance for women with borderline oligohydramnios as there is an increased risk of fetal distress and cesarean section in this group. Regarding the perinatal outcome, there were significant differences in rates of growth-restricted babies between both groups. Growth restricted babies were more among women with borderline AFI when compared to those with normal AFI. ${ }^{15}$ Jamal et al also reported a fourfold increased incidence of growth-restricted babies among women with borderline oligohydramnios. Neonates with an APGAR score less than 7 at 5 minutes of life were significantly more among women with borderline oligohydramnios (7.3\%) as compared to women with normal AFI (2.6\%). The rate of NICU admission was also higher among women with borderline oligohydramnios $(12.6 \%)$ as compared to those with normal AFI $(6.6 \%)$. But statistically, no significant difference was made out concerning NICU admissions between women with normal AFI and women with borderline AFI. ${ }^{16}$ Jeng et al also reported an increased rate of NICU admission (19.05\%) but no difference in APGAR score. Two neonatal deaths were reported among women with borderline AFI and no death among those with normal AFI. Though the differences in perinatal mortality rate were not statistically significant, there must be extra regarding monitoring of cases with borderline AFI. ACOG cites that oligohydramnios and polyhydramnios were among the conditions requiring antepartum fetal surveillance in addition to other pregnancy-associated conditions. However, borderline oligohydramnios was not cited as one among the conditions requiring antepartum fetal surveillance. ${ }^{17}$ In this era of value-based care, questions concerning the need for heightened antepartum surveillance per se for borderline oligohydramnios arise through various studies that report adverse perinatal outcomes in cases of borderline oligohydramnios. But by the cumulative analysis of various studies, it will be reasonable to conclude that antepartum surveillance for borderline oligohydramnios is indicated in cases associated with fetal growth restriction or suboptimal fetal growth. ${ }^{18-20}$

\section{CONCLUSION}

Borderline oligohydramnios, when compared with normal liquor volume is associated with increased incidence of meconium staining of amniotic fluid, fetal distress and caesarean delivery. There is also a higher likelihood of babies with low APGAR scores at 5 minutes, fetal growth restriction, and fetal distress. Hence increased antepartum surveillance and better monitoring are mandatory in cases with borderline oligohydramnios to avoid adverse perinatal outcomes.

\section{Funding: No funding sources \\ Conflict of interest: None declared \\ Ethical approval: The study was approved by the Institutional Ethics Committee}

\section{REFERENCES}

1. Akhter H, Guha K, Daisy KP. Amniotic Fluid Index in High-Risk Pregnancies and Pregnancy Outcome. Dinajpur Med Col J. 2010;3:1-5.

2. Ali HS. Assessment of amniotic fluid index in normal pregnancy at a tertiary care hospital setting. J Ayub Med Coll Abbottabad. 2009;21:149-51.

3. Anderson D, Yang Q, Hohimer A, Faber J, Gi Raud G, Davi SL. Intermembranous absorption rate is unaffected by changes in amniotic fluid composition. Am J Physiol Renal Physiol. 2005;288:964-8. 
4. Asgharnia M, Faraji R, Salamat F, Ashrafkhani B, Heirati SFD, Naimian S. Perinatal outcomes of pregnancies with borderline versus the normal amniotic fluid index. Iran $\mathrm{J}$ Reprod Med. 2013;11:705-10.

5. Banks EH, Miller DA. Perinatal risks associated with the borderline amniotic fluid index. Am J Obstet Gynecol. 1999;180:1461-3.

6. Banks EH, Miller DA. Perinatal risks associated with the borderline amniotic fluid index. Am J Obstet Gynecol. 1999;180:1461-3.

7. Baron C, Morgan MA, Garite TJ. The impact of amniotic fluid volume assessed intrapartum on perinatal outcome. Am J Obstet Gynecol. 1995; 173:167-74.

8. Baron C, Morgan MA, Garite TJ. The impact of amniotic fluid volume assessed intrapartum on perinatal outcome. Am J Obstet Gynecol. 1995; 173:167-74.

9. Camu H, Martens G, Ruyssinck G, Amy JJ. Outcome after elective labor induction in nulliparous women: a matched cohort study. Am J Obstet Gynecol. 2002;186:240-4.

10. Conway DL, Adkins WB, Schroeder B, Langer O. Isolated oligohydramnios in the term pregnancy: Is it a clinical entity? J Matern Fetal Med. 1998;7:197-200.

11. Ehrenthal SB, Jiang X, Strobino DM. Labor induction and the risk of cesarean delivery among nulliparous women. Obstet Gynecol. 2010;116:35-42.

12. Nike S. Reddy G, Ghike NW. Increasing severity of oligohydramnios: A risk factor for outcome. J South Asian Feder Obst Gynae. 2013;5:8-10.
13. Gumus II, Koktener A, Turhan NO. Perinatal outcome of pregnancies with borderline amniotic fluid index. Arch Gynecol Obstet. 2007;276:17-9.

14. Haas DM, Magann EF. External cephalic version with an amniotic fluid index <or =10: a systematic review. J Matern Fetal Neonatal Med. 2005;18:249-52.

15. Hashimoto K, Kasdaghi T, Sharoky C. Perinatal outcome of mildly decreased AFI in the third trimester. Ultrasound Obstet Gynecol. 2011;38(1):53.

16. Jamal A, Abbasi S, Mesdaghima S. Borderline amniotic fluid index and adverse perinatal outcome. Ultrasound Obstet Gynecol. 2008;32:391-3.

17. Jeng CJ, Lee JF, Wang KG, Yang YC, Lan CC. The decreased amniotic fluid index in term pregnancy. $\mathrm{J}$ Reprod Med. 1992;37:789-92.

18. Karim R, Jabeen S, Pervaiz F, Wahab S, Yasmeen S, Raees M. Decreased amniotic fluid index and adverse pregnancy outcome at term. PMI. 2010;4:307-11.

19. Kwon JY, Kwon HS, Kim YH, Park YW. Abnormal Doppler velocimetry is related to adverse pregnancy outcomes for the borderline amniotic fluid index in the third trimester. J Obstet Gynecol Res. 2006;32:545-9.

20. Kwon JY, Kwon HS, Kim YH, Park YW. Abnormal Doppler velocimetry is related to adverse pregnancy outcomes for the borderline amniotic fluid index in the third trimester. J Obstet Gynecol Res. 2006;32:545-9.

Cite this article as: Vennila M, Deepika S.

Borderline oligohydramnios in term pregnancy and it's relation with pregnancy outcome. Int J Reprod Contracept Obstet Gynecol 2021;10:505-10. 